\title{
Possible Climate Change Impacts and Policy-Relevant Messages
}

\section{Coordinating Lead Authors}

Chirag Dhara, Indian Institute of Tropical Meteorology (IITM-MoES), Pune, India, e-mail: chirag.dhara@tropmet.res.in (corresponding author)

R. Krishnan, Indian Institute of Tropical Meteorology (IITM-MoES), Pune, India

\section{Review Editor}

Dev Niyogi, Purdue University, West Lafayette, IN and University of Texas at Austin, Austin, TX, USA

\section{Corresponding Author}

Chirag Dhara, Indian Institute of Tropical Meteorology (IITM-MoES), Pune, India, e-mail: chirag.dhara@tropmet.res.in 
The Paris Agreement 2015, framed during the twenty-first Conference of Parties (COP21), called on all nations to collectively limit global warming to $2^{\circ} \mathrm{C}$ below preindustrial levels and to pursue efforts to limit the increase to $1.5^{\circ} \mathrm{C}$. In this context, the IPCC published a Special Report in October 2018 on the relative impacts of global warming levels of 1.5 and $2^{\circ} \mathrm{C}$. According to the report, the impacts of a $2^{\circ} \mathrm{C}$ rise are not only severe but also considerably larger than for $1.5^{\circ} \mathrm{C}$ on a global scale.

Despite the dire projections from the IPCC Special Report, whether the $1.5^{\circ} \mathrm{C}$ target is practically achievable is contested. The pace at which human activities have already changed the climate since the pre-industrial era is unprecedented in the history of modern civilization, and the world is presently on course to far exceed the Paris targets. At current greenhouse gas emissions trajectories, global average temperature may rise $3-5^{\circ} \mathrm{C}$, perhaps higher if tipping points ${ }^{1}$ are triggered, above pre-industrial temperatures by the end of the twenty-first century. However, the extent and rate of climate change as well as its impacts will vary across the planet.

Chapters 1-11 have assessed the observed and future changes in climate over the Indian region. However, the impacts of these changes were not discussed since they lie outside the scope of this report.

This concluding chapter is an essay briefly discussing the possible impacts of climate change on India and the policy relevance of this report. Focused impact assessment studies based on the findings in the previous chapters can be the foundation for adaptation and mitigation strategies.

\subsection{Potential Impacts Over India}

The rapid changes in India's climate projected by climate models will place increasing stress on the country's natural ecosystems, agricultural output, and fresh water resources, while also causing escalating damage to infrastructure. These portend serious consequences for the country's biodiversity, food, water and energy security, and public health. In the absence of rapid, informed and far-reaching mitigation and adaptation measures, the impacts of climate change are likely to pose profound challenges to sustaining the country's rapid economic growth, and achieving the sustainable development goals (SDGs) adopted by UN Member States in 2015 .

The impact of climate change on the availability of fresh water is a critical area of concern for India. Continued global warming through the twenty-first century, together with the high probability of future reductions in anthropogenic

\footnotetext{
${ }^{1}$ Tipping points refer to critical thresholds in a system that, when exceeded, can lead to an abrupt change in the state of the system, often with an understanding that the change is irreversible.
}

aerosol emissions from North America, Europe, and Asia, will likely intensify summer monsoon precipitation and its variability over India. The growing propensity for droughts and floods because of changing rainfall patterns caused by climate change would be detrimental to surface and groundwater recharge, posing threats to the country's water security.

Likewise, the country's food security may be placed under progressively greater pressure due to rising temperatures, heat extremes, floods, droughts and increasing year-to-year rainfall variability that can disrupt rain-fed agricultural food production and adversely impact crop yield.

Studies indicate that climate change may seriously compromise human health in the absence of risk mitigation, adaptation, or acclimatization, particularly among children and the elderly. Higher temperatures, extreme weather events, and higher climate variability have been associated with an elevated risk of heat strokes, cardiovascular and neurological diseases, and stress-related disorders. Heat stress in urban areas is often compounded by the heat island effect. Warmer, higher moisture conditions, on average, are also more favourable for the spread of vector-borne diseases such as malaria and dengue fever. In addition, a decrease in the availability or affordability of food and potable water caused by climate change may lead to reduced nutritional intake, particularly among economically weaker sections.

Rising temperatures are also likely to increase energy demand for space cooling, which if met by thermal power would constitute a positive feedback to global warming by increasing GHG emissions. In addition, thermal power plants require substantial amounts of water for cooling to generate electricity. Power plants sited inland draw freshwater largely from dam reservoirs, rivers and canals. A rise in water withdrawal by power plants would directly compete with water withdrawal for agriculture and domestic consumption, particularly in water stressed areas. On the other hand, power plants sited around the coast that use sea water for cooling are vulnerable to damage from sea-level rise, cyclones, and storm surge. In short, climate change could impact the reliability of the country's energy infrastructure and supply.

India's long coastline, where some of its largest cities are located, is among the most densely populated regions of the planet, making it exceedingly vulnerable to the impacts of sea-level rise. Potential coastal risks include loss of land due to increased erosion, damage to coastal projects and infrastructure such as buildings, roads, monuments, and power plants, salinization of freshwater supplies and a heightened vulnerability to flooding. Higher sea levels and receding coastlines escalate the destructive potential of storm surge associated with cyclonic storms. These impacts of sea-level rise may be additionally compounded by land subsidence 
occurring in parts of the country due to factors such as the declining water table depth.

Several regions in India are global biodiversity hotspots with numerous endemic species of plants and animals. With the climate changing more rapidly than the usual pace of evolutionary adaptability of many species, they may face increasing threats on account of these changes. Species specially adapted to narrow environmental conditions are likely to be affected the most.

The risks posed by climate change can be considerably magnified when a cascade of climate-related hazards overlap or follow one another. For instance, a region may experience an abnormally long or intense summer heat wave followed by intense monsoon floods that alternate with lengthening dry spells. Low-lying coastal zones, especially on India's east coast, may witness rising sea levels damaging property and increasing groundwater salinity. A rise in cyclone intensities will likely result in increasing inundation from the accompanying storm surges that turn proximate agricultural lands and lakes saline, and imperil wildlife. Such sequences of events will become increasingly frequent if anthropogenic climate change continues unimpeded.

The aggregate result of these impacts according to the recent IPCC Special Report on the difference in impacts between $1.5^{\circ} \mathrm{C}$ versus $2^{\circ} \mathrm{C}$ warming is that tropical countries such as India are projected to experience the largest impacts on economic growth because of climate change.

\subsection{Policy-Relevant Messages}

Due to the multiplicity of threats posed by climate change, it is crucial to make vulnerability assessment central to long-term planning for developing adaptation and mitigation strategies.

Climate change impacts will differ widely across the country depending on local context such as geography (e.g. coastal, inland or mountains) and climate (e.g. arid or wet) among others. Inclusion of detailed, regional-scale climate change risk assessments would help develop region and sector-specific mitigation and adaptation measures to reduce vulnerability to climate change.

India's climate change adaptation and mitigation response is achievable by a greater emphasis on widening observational networks, sustained monitoring, expanding research on regional changes in climate and their impacts, development of integrated, multiscale models that are capable of aiding predictions, scenario synthesis and providing information required for vulnerability assessment, and by continued investment in education and outreach programs including national and international collaborative partnerships. For instance, networks of tide gauges with GPS along the Indian coastline would help monitor local changes in sea level, climate models would help project future changes, and outreach would help inform the requisite adaptation measures in coastal communities and cities. Outreach and communication of climate change risk to district and village-level communities would facilitate water-harvesting and farming decisions needed to adapt to a changing climate. Additionally, dedicated educational programmes from school to university would vastly improve awareness about climate change and its implications for humans and natural ecosystems. Such programs could encourage young minds to contribute through individual and collective efforts that are crucial for climate action.

It is necessary to develop useful to usable (U2U) research and application agenda that can translate research to on-ground, effective decision tools for adapting to climatic change. Cities being uniquely impacted by heat stress and localized flooding, there is a pressing need for research and strategies that are directed towards improving resilience in Indian cities. Specific additional examples such as passive reduction of indoor temperatures, water conservation and rainwater harvesting, groundwater regulation, reversing land degradation, reduction in food and water wastage, waste segregation and recycling, low impact urban development, expansion of urban green spaces and urban farming, pollution control, increasing the area under irrigation and improving the efficiency of agricultural water use, forest conservation and proactive afforestation, construction of coastal embankments and mangrove restoration, improvement in disaster response, phasing out fossil fuels and transition to renewables, electrification, expansion of walking, bicycling and public transport infrastructure, and carbon taxation, among others, have been successfully implemented in parts of the country and the world to reduce risk from climate change.

Equity and social justice are critical to building climate resilience since the most vulnerable people such as the poor, the disabled, outdoor labourers and farmers will bear the brunt of climate change impacts.

\subsubsection{Multiple Benefits of Climate Change Action}

Just as climate change impacts cascade into complex multi-hazards, several of these policy measures are likely to deliver multiple benefits. For instance, a strategic transition to renewables would reduce both $\mathrm{GHG}$ emissions as well as water consumption required to cool thermal power plants. Low impact development and green building infrastructure can reduce both urban heating and air pollution. A reduction in air pollution would greatly benefit human and environmental health, improve the efficiency of solar energy generation, and even potentially aid in increasing the quantum 
of monsoon rainfall over India (see Chaps. 1 and 3). An increase in rainfall together with measures for water harvesting would aid the restoration of groundwater levels. Restoration of groundwater levels would not only improve water security and resilience to droughts but also help check land subsidence, consequently reducing the impacts of sea-level rise and storm surge.

Ambitious afforestation efforts likewise offer myriad benefits. Aside from mitigating climate change through carbon sequestration, trees also enhance resilience to flash floods and landslides by improving soil retention, improve resilience to droughts by increasing percolation of surface water into the soil, improve resilience of coastal infrastructure and habitation by reducing coastline erosion due to storm surges and sea-level rise, reduce vulnerability to extreme heat by reducing ambient temperatures, and support native wildlife and biodiversity. In short, forests and urban green spaces will deliver substantial economic benefits to the country by mitigating a wide range of the expected impacts of climate change in India and is the safest, most reliable means of realizing several of India's sustainable development goals.

Open Access This chapter is licensed under the terms of the Creative Commons Attribution 4.0 International License (http:// creativecommons.org/licenses/by/4.0/), which permits use, sharing, adaptation, distribution and reproduction in any medium or format, as long as you give appropriate credit to the original author(s) and the source, provide a link to the Creative Commons license and indicate if changes were made.

\subsection{Summary}

In conclusion, changes in climate need to be considered as a part of a complex system. The merits and trade-offs of different policy measures need to be assessed so as to extend well beyond climate change mitigation and adaptation. This warrants a continued and sustained push for research, cooperative inter-disciplinary work and a close coordination between researchers and policy-makers to convert knowledge into action.

This report has, using observations as well as model studies, assessed the extent and rate of climate change in India and how it may evolve in future. The impacts of these changes on infrastructure, environmental and public health can hamper efforts towards attaining India's developmental goals and impede the country's economic growth. Addressing these challenges will require developing periodically updated regional-scale assessments of climate change and its impacts, evaluating the efficacy of existing policies, learning from sustainable practices across India and around the world, and responding dynamically in line with scientific advancements.
The images or other third party material in this chapter are included in the chapter's Creative Commons license, unless indicated otherwise in a credit line to the material. If material is not included in the chapter's Creative Commons license and your intended use is not permitted by statutory regulation or exceeds the permitted use, you will need to obtain permission directly from the copyright holder. 